\title{
Método de aislamiento, cullívo y precondicionamiento con hipoxia de células madre derivadlas de tejidido adiposo en ratas
}

\section{Method of isolation, culture and hypoxia preconditioning of adipose tissue stem cells in rats}

Miguel L. OBAÍD*, Romina, RIQUELME*, Wilfredo CALDERÓN**

Maravilla RAUE**, Mariana ROJAS ${ }^{\star \star \star \star}$

\section{Resumen}

Abstract

Introducción y objetivo. Las células madre son candidatas terapéuticas para una amplia gama de enfermedades. Resultan de gran interés en Cirugía Plástica para el tratamiento de heridas crónicas, transferencia de tejido adiposo y colgajos.

El objetivo de este estudio es describir el método de aislamiento, cultivo y caracterización de células madre derivadas de tejido adiposo y cómo estas pueden precondicionarse con hipoxia y generar cambios in vitro en su capacidad proliferativa y migratoria. El trabajo es un complemento didáctico a otro publicado por nosotros en esta misma revista utilizando esta metodología en comparación al grupo de retardo de colgajo y grupo control en colgajos cutáneos aleatorizados en ratas.

Métodos. Obtuvimos las células madre de tejido graso ínguino -abdominal de ratas adultas: 10 en el grupo de células madre derivadas de tejido adiposo y otras 10 en el grupo de células madre derivadas de tejido adiposo precondicionadas con hipoxia $\left(2 \% \mathrm{O}_{2}\right.$ y $\left.5 \% \mathrm{CO}_{2}\right)$. Realizamos análisis morfológico directo y con inmunofluorescencia con el marcador vimentina y CD90 y estudio de proliferación y migración celular in vitro.

Resultados: Utilizamos en promedio $1.64+/-1.13$ gr de tejido adiposo en el grupo sin precondicionamiento y $0.93+/-0.34 \mathrm{gr}$ en el grupo con precondicionamiento con hipoxia para el aislamiento. Las células madre derivadas de tejido adiposo precondicionadas con hipoxia presentaron un aumento de la capacidad migratoria a las 24 horas de $2.44+/-0.85 \mathrm{~mm}$ frente a $2.24+/-0.82 \mathrm{~mm}(\mathrm{p}<0.01)$ y proliferativa $5.42 \times 10^{5}+/-1.03 \times 10^{5}$ céls $/ \mathrm{ml}$ frente a $3.26 \times 10^{5}+/-8.61$ $\mathrm{x} 10^{4}$ céls $\left./ \mathrm{ml}\right)(\mathrm{p} \leq 0.001)$ de forma significativa en comparación a las sin precondicionamiento.

Conclusiones. Describimos en detalle un método de precondicionamiento de células madre mediante hipoxia. Logramos potenciar el efecto de las células madre aumentando en forma significativa su capacidad migratoria y proliferativa de forma precoz.

Palabras clave Células madre, Células madre tejido adiposo, Precondicionamiento, Hipoxia.

\section{Nivel de evidencia científica Recihido [esta versión] Aceptado}

$5 c$ Terapéutico 26 agosto/2018 12 mayo/2019
Background and objective. Stem cells are therapeutic candidates for a wide range of diseases. They are of great interest in Plastic Surgery for the management of chronic wounds, adipose tissue transfer and flaps.

The objective of this study is to describe the method of isolation, culture and characterization of stem cells derived from adipose tissue and how these can be preconditioned with hypoxia and generate in vitro changes in their proliferative and migratory capacity. This study is a didactic supplement to a paper published by us in this same journal using this methodology in comparison to the group of flap delay and control group in skin flaps randomized in rats.

Methods. Stem cells were obtained from inguinal-abdominal fatty tissue of adult rats: 10 in the group of stem cells derived from adipose tissue and another 10 in the group of stem cells derived from adipose tissue preconditioned with hypoxia $(2 \% \mathrm{O} 2$ and $5 \% \mathrm{CO} 2)$. Direct morphological analysis was carried out and with immunofluorescence (vimentin and CD90 marker). Study proliferation and in vitro cell migration was performed.

Results. An average of $1.64+/-1.13$ gr of adipose tissue of the inguinoabdominal area was used in the group of stem cells without preconditioning and $0.93+/-0.34$ gr. in the group with hypoxic preconditioning for the isolation. Stem cells derived from adipose tissue preconditioned with hypoxia showed an increase in migratory capacity at 24 hours of $2.44+/-0.85 \mathrm{~mm} \mathrm{v} / \mathrm{s} 2.24+/-0.82 \mathrm{~mm}(\mathrm{p}<0.01)$ and proliferative of $5.42 \times 10^{5}+/-1.03 \times 10^{5}$ cells $/ \mathrm{ml} \mathrm{v} / \mathrm{s} 3.26 \times 10^{5}+/-$ $8.61 \times 10^{4}$ cells $\left./ \mathrm{ml}\right)(\mathrm{p} \leq 0.001)$ significantly compared to those without preconditioning.

Conclusions. A method of preconditioning stem cells by hypoxia is described in detail. It is possible to enhance the effect of the stem cells, significantly increasing their early migratory and proliferative capacity.

Key words Stem cells, Adipose-derived stem cells, Preconditioning, Hypoxia.

\section{Level of evidence Received [this version] Accepted} $5 c$ Therapeutic 26 Augost/2018

Conflicto de intereses: los autores declaran no tener ningún interés financiero relacionado con el contenido de este artículo.

Financiación: No hubo fuentes externas de financiación para este trabajo.

\footnotetext{
Médico Residente de Cirugía General, Hospital del Salvador, Universidad de Chile, Magíster en Ciencias Biomédicas Mención Morfología, Universidad de Chile, Santiago, Chile

** Cirujano Plástico, Hospital del Salvador, Santiago, Chile

*** Anátomopatologo, Universidad Católica de Chile, Santiago, Chile

**** Profesor Asociado, Laboratorio de Embriología Comparada, Universidad de Chile, Santiago, Chile
} 
Introducción

Las células madre mesenquimales son candidatas terapéuticas para una amplia gama de enfermedades humanas. Estas células pueden migrar a zonas de injuria tisular para facilitar la reparación del tejido. Una vez en el lugar, pueden diferenciarse en distintos componentes del tejido lesionado. Sin embargo, su efecto clave es probablemente su capacidad para ejercer efectos inmunomoduladores y para secretar factores que promueven la reparación de tejidos. ${ }^{(1)}$

El uso de células madre se ha investigado como tratamiento complementario para una gran variedad de enfermedades tales como: accidente cerebrovascular isquémico, esclerosis múltiple, isquemia miocárdica, enfermedad pulmonar obstructiva crónica, fibrosis pulmonar idiopática, insuficiencia hepática crónica, insuficiencia renal aguda, enfermedad inflamatoria intestinal y osteoartritis. ${ }^{(1)}$ En Cirugía Plástica también han generado gran interés, especialmente para el tratamiento de heridas crónicas, transferencia de tejido adiposo para procedimientos estéticos y reconstructivos con mejora en la retención de injerto graso y por ende disminución de su reabsorción ${ }^{(2)}$ y para el aumento en la vitalidad de los colgajos. ${ }^{(3)}$

Existen distintas fuentes disponibles para la obtención de células madre: células troncales embrionarias (Embryonic Stem Cells, ESCs) y células troncales adultas. ${ }^{(4)}$ A pesar del gran potencial terapéutico encontrado en las ESCs por su capacidad de autorrenovación y pluripotencialidad, presentan limitaciones en la práctica clínica por consideraciones éticas, manipulación genética y regulación celular. ${ }^{(5)}$ En contraste, las células madre adultas, por naturaleza, son inmunocompatibles y no presentan limitaciones éticas para su uso. ${ }^{(5)}$ Estas últimas inicialmente se aislaron en médula ósea (Bone Marrow Mesenchymal Stem Cells, BM-MSCs), ${ }^{(6)}$ luego en el cordón umbilical y últimamente en el tejido adiposo (ASCs). ${ }^{(5)}$

Las ASCs tienen la ventaja de encontrarse en grandes cantidades en el individuo, poseen una extensa capacidad de autorrenovación, se pueden aislar fácilmente y poseen potencial de diferenciación en distintas líneas celulares, tales como: adipocitos, osteoblastos, condrocitos, neuronas o miocitos en respuesta a distintos factores inductores. ${ }^{(7)}$

Estas células se caracterizan por su morfología que recuerda a los fibroblastos, presentan propiedades adhesivas y de autorrenovación, así como la capacidad de diferenciarse in vitro en tres tejidos mesodérmicos tales como óseo, cartilaginoso y adiposo. Expresan marcadores de superficie CD29, CD44, CD90 y CD105 con ausencia de expresión de marcadores hematopoyéticos y HLA-DR. ${ }^{(7,8)}$ Otro marcador es la vimentina, proteína que se encuentra en los filamentos intermedios de las células mesenquimales. ${ }^{(9,10)}$

Gimble y col. ${ }^{(11)}$ sugieren que para que las células madre se apliquen en Medicina Regenerativa deben cumplir los siguientes criterios:

- Encontrarse en abundantes cantidades (de millones a billones de células).

- Obtenerse a través de un procedimiento mínimamente invasivo.

- Poseer la capacidad de diferenciarse en múltiples linajes celulares de una manera regulable y reproducible.

- Trasplantarse en forma segura y efectiva a un huésped autólogo o alógenico.

Ser manipulables de acuerdo a las guías de buena práctica.

La aplicabilidad de las ASCs resulta atractiva por su fácil obtención a través de lipoaspirado, que va desde 100 $\mathrm{ml}$ a más de 31 . y que rutinariamente es eliminado. ${ }^{(11,12)}$ Para la obtención de tejido adiposo es preferible la región abdominal en comparación a otras áreas, como de la cadera y el muslo, por la mayor cantidad en forma significativa de ASCs. Las células ASCs en distintas áreas corporales no varían su potencial de diferenciación en otras líneas celulares ni en la expresión de marcadores de superficie celular, ni tampoco influye la edad en la frecuencia de aparición de ASCs. ${ }^{(13)}$

El uso de BM-MSCs para aumentar la supervivencia del colgajo no parece ser mejor respecto al de ASCs, sin embargo corresponde a un procedimiento invasivo y doloroso para la recolección de estas células, encontrarse proporcionalmente en menor cantidad en el individuo en comparación al tejido adiposo, y por su disminución de la capacidad de proliferación y diferenciación en otros linajes celulares con la edad. ${ }^{(7)}$

El uso de células madre ha resultado promisorio y llama la atención por su efecto potencial global. A diferencia de los métodos farmacológicos que actúan frente a un factor en específico (angiogénesis, vasodilatación, simpaticolíticos, secuestro de radicales libres, inhibición de prostaglandinas, etc.), estas células, en teoría por su capacidad de diferenciación en múltiples linajes celulares, capacidad de anidamiento (homing) o de localizarse en el tejido de interés y permanecer allí, inmunomodulación, promoción de la reparación y regeneración directa de los tejidos dañados, por su habilidad de autorrenovación y diferenciación en múltiples linajes celulares, se convierten en candidatas terapéuticas prometedoras. ${ }^{(1)}$

A pesar de que rápidamente el tratamiento con células madre se ha desarrollado como un tratamiento regenerativo potencial para varias enfermedades, se han ignorado 
varios aspectos y problemas tales como: diferenciación celular, sobrevida de las células trasplantadas en un lugar hostil sometidas a isquemia e hipoxia, citotoxicidad, especies reactivas de oxígeno, respuesta inflamatoria, activación de cascada apoptótica, entre otros. ${ }^{(14)}$ Es por ello que se ha podido potenciar el efecto de las células madre a través del precondicionamiento.

Se han empleado varios agentes precondicionantes en las células madre mediante un insulto subletal a través de isquemia, hipoxia, anoxia, ácido sulfhídrico $\left(\mathrm{H}_{2} \mathrm{~S}\right)$, peróxido de hidrógeno $\left(\mathrm{H}_{2} \mathrm{O}_{2}\right)$ monóxido de carbono $(\mathrm{CO})^{14}$ y fotobiomodulación. ${ }^{(15)}$

La exposición a hipoxia a un nivel no letal aumenta significativamente la tolerancia celular y presenta una mejora en las propiedades regenerativas de las células madre. A través de características de mejora en la sobrevida, en los efectos paracrinos con obtención de un mejor soporte trófico, expresión de factores tróficos estimulantes de la angiogénesis, activación de mediadores antioxidantes, mejor tolerancia en el sitio de lesión tras su administración, aumento de la proliferación y capacidad de migración a regiones isquémicas o alrededor de un tejido infartado. ${ }^{(14)}$

La exposición a hipoxia se puede realizar a concentraciones del 1 al 5\% de $\mathrm{O}_{2}$. La exposición a concentraciones del $1 \%$ es óptima para la promoción de las propiedades proangiogénicas a través de un aumento de la expresión del VEGF, mientras que la exposición al 5\% de $\mathrm{O}_{2}$ presenta mayor proliferación celular. ${ }^{(16,17)}$

El propósito de este estudio es describir el método de aislamiento y cultivo de células madre derivadas de tejido adiposo (ASCs), caracterización morfológica y mediante inmunofluorescencia y cómo estas pueden precondicionarse con hipoxia y generar cambios in vitro en su capacidad proliferativa y migratoria. Esta metodología ya fue utilizada por nosotros en un estudio publicado en esta misma revista en el que comparamos distintos métodos para disminuir la necrosis del colgajo cutáneo aleatorio, utilizando células madre derivadas de tejido adiposo con y sin precondicionamiento con hipoxia, retardo de colgajo y grupo control. Además proponemos una clasificación de necrosis del colgajo según hallazgos macroscópicos e histopatológicos. ${ }^{(17)}$

\section{Material y método}

\section{Obtención de ASCs}

Obtenemos el tejido adiposo en ratas Sprague-Dawley de sexo masculino, de peso entre 300-500 gr, intervenidas bajo las normas bioéticas del ICBM (Instituto de Ciencias Biomédicas de Santiago, Chile) para la experimentación con animales de laboratorio: 10 ratas para células madre derivadas de tejido adiposo adultas (ASCs) y 10 ratas para células madre derivadas de tejido adiposo adultas precondicionadas con hipoxia (ASCs-H). Las ratas son anestesiadas con ketamina $80 \mathrm{mg} / \mathrm{kg}$ y xilacina $8 \mathrm{mg} / \mathrm{kg}$ vía intramuscular. Preoperatoriamente se les administra penicilina benzatina $40.000 \mathrm{U} / \mathrm{Kg}$ también intramuscular.

Fraccionamos el tejido adiposo del área abdominal de la rata y lo lavamos con solución buffer-fosfato 1x (DPBS, GIBCO, Cod: 14190144) (Fig. 1), digerido con colagenasa tipo II al $0.15 \%$ (Sigma-Aldrich, Cod: C6885) durante 60 min a $37^{\circ} \mathrm{C}$ y neutralizado con medio de cultivo (DMEM, GIBCO, Cod:11995) 10\% de suero bovino fetal (FBS, GIBCO, Cod: 10270), 1\% de antibióticos y antimicóticos (Antibiotic-Antimycotic 100X, GIBCO, Cod: 15240). Posteriormente se centrifuga du-

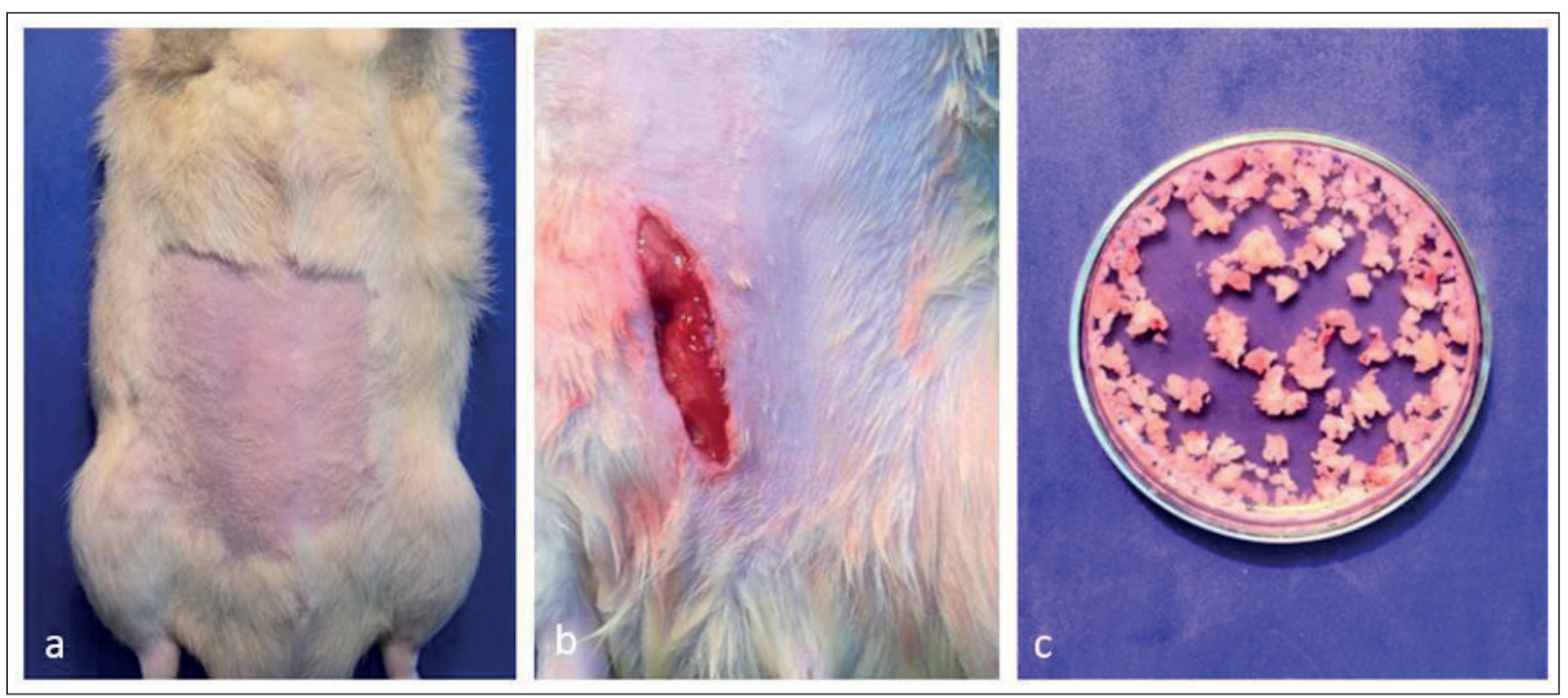

Figura 1. A. Rata en posición supina con rasuración del área ínguino-abdominal. B. Incisión con bisturí y exposición de tejido graso subcutáneo. C. Tejido graso fraccionado en placa de Petri con solución buffer fosfato 1x. 


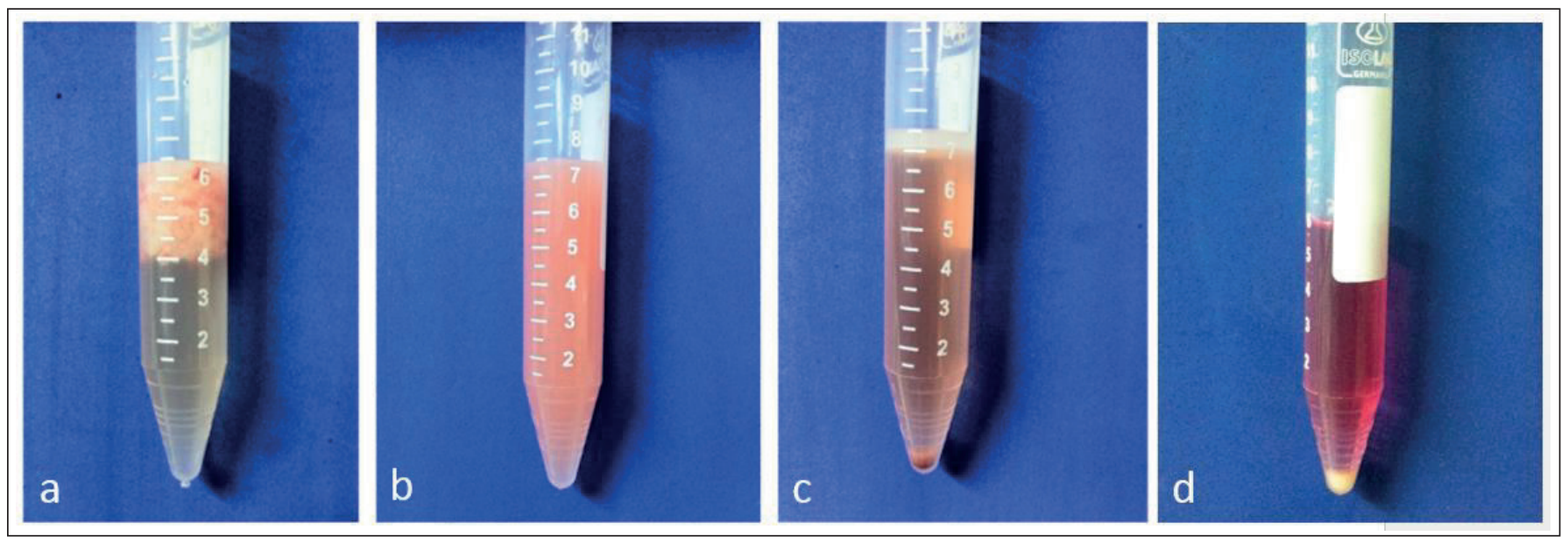

Figura 2. A. Recolección de tejido adiposo fraccionado en solución buffer fosfato 1x y colagenasa tipo II. B. Tejido graso digerido mediante colagenasa tipo II. C. Obtención del pellet tras la centrifugación. C. Resultado final tras la expansión de las ASCs al cabo de 10 días, tripsinización y centrifugación.

rante 10 min a $1200 \mathrm{~g}$. El pellet obtenido es resuspendido en medio de cultivo y analizado (Fig. 2). Mantenemos las ASCs en condiciones de normoxia $\left(21 \% \mathrm{O}_{2}-5 \% \mathrm{CO}_{2}\right)$, mientras que con las ASCs-H, en la mitad del proceso de expansión, realizamos tripsinización $(0.25 \%$ Trypsin-EDTA (1X), GIBCO,Cod:25200) de las células para luego colocarlas en DMEM preparado y sometido a hipoxia durante 24 horas en cámara de hipoxia (Modular Incubator Chamber). Tras 72 horas en estas condiciones $\left(2 \% \mathrm{O}_{2}-5 \% \mathrm{CO}_{2}\right)$ procedemos a la tripsinización nuevamente para realizar el conteo celular con hemocitómetro.

\section{Inmunohistoquímica}

Colocamos un cubreobjeto estéril sobre cada uno de los cultivos durante el segundo pasaje para la adhesión celular. Después de 3 días, extraemos el cubreobjeto y sumergimos en una placa de Petri durante 6 minutos en metanol a $-20{ }^{\circ} \mathrm{C}$ y 1 minuto en acetona a $-20^{\circ} \mathrm{C}$, para luego pasarlo por tampón fosfato durante 5 minutos y cubrirlo con suero de cabra 1/10 en PBS-BSA al 2\%, dejándolo en cámara húmeda durante 30 minutos. Utilizamos el anticuerpo primario vimentina (Dako) $1 / 100$ y el anticuerpo CD90 (Thy-1) 1/100 (Chemicon). Lo dejamos 1 noche en refrigeración. Posteriormente empleamos IgG FITC (Vector) 1/200 como anticuerpo secundario. Utilizando la técnica de Propidio (Polysciences) 1/500 es posible destacar la cromatina de los núcleos en color rojo. Montaje en medio acuoso (Dako Faramount, S3025). Visualización en microscopio de fluorescencia UV con filtro mixto.

\section{Estudio de proliferación celular}

Durante el segundo pasaje de un cultivo celular en condiciones de normoxia, se tripsiniza y tomamos 2 muestras que colocamos en 2 frascos de cultivo celular en concentraciones equivalentes, uno se mantiene en condiciones de normoxia $\left(21 \% \mathrm{O}_{2}-5 \% \mathrm{CO}_{2}\right)$ y el otro en hipoxia $\left(2 \% \mathrm{O}_{2}-5 \% \mathrm{CO}_{2}\right)$ (Modular Incubator Cham- ber). Mantenemos durante 24 horas en estas condiciones y nuevamente procedemos a la tripsinización, obteniendo 10 muestras de ambos cultivos para luego realizar el conteo celular mediante hemocitómetro. A partir de otro cultivo celular, realizamos este mismo procedimiento pero haciendo el conteo celular a las 72 horas en las condiciones descritas.

\section{Estudio de migración celular}

De un cultivo celular, durante el segundo pasaje en condiciones de normoxia, se tripzinizan las células y se colocan sobre 16 cubreobjetos en cantidades equivalentes. Colocamos 8 cubreobjetos en placas de Petri en condiciones de normoxia $\left(21 \% \mathrm{O}_{2}-5 \% \mathrm{CO}_{2}\right)$ y las 8 restantes en hipoxia $\left(2 \% \mathrm{O}_{2}-5 \% \mathrm{CO}_{2}\right)$. Esperamos confluencia celular del $90 \%$ para posteriormente, de un vértice del cubreobjeto, retirar $10 \mathrm{~mm}$ de células adheridas con micropipeta y tomar registro fotográfico con cámara Canon Power Shot A640. A las 24 horas realizamos un nuevo registro fotográfico y mediante el programa ImageJ 1.45 medimos en milímetros la migración celular (Fig. 3).

\section{Análisis estadístico}

Utilizamos las pruebas estadísticas de $\mathrm{T}$ de Student con significancia estadística $\mathrm{p} \leq 0.05$ y el software MedCalc 12.5.

\section{Resultados}

\section{Aislamiento y cultivo de las ASCs en condiciones de normoxia y en hipoxia \\ Utilizamos en promedio $1.64+/-1.13 \mathrm{gr}$ de tejido adiposo del área ínguinoabdominal en el grupo de ASCs y $0.93+/-0.34$ gr en el grupo ASCs-H para el ais- lamiento de ASCs. Logramos una concentración celular de ASCs $9.95 \times 10^{6}+/-7.3 \times 10^{6}$ céls $/ \mathrm{ml}$ y en el grupo}




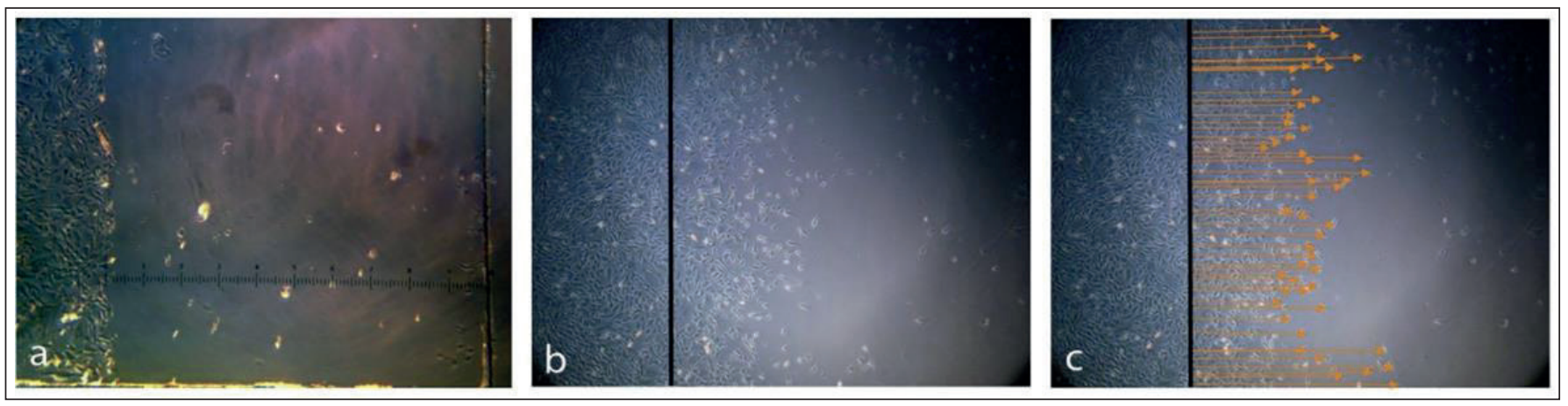

Figura 3: A. A la izquierda, retirada de $10 \mathrm{~mm}$ de las células adheridas al cubreobjeto con micropipeta, tomando como referencia el borde del cubreobjeto (Microscopio óptico invertido, visualización directa y sin tinción. Aumento 10X). B y C. Fotografías obtenidas a las 24 horas: estudio de migración de las células que se alejaron respecto al punto de partida (línea negra). (Microscopio óptico invertido, visualización directa y sin tinción. Aumento 10X).

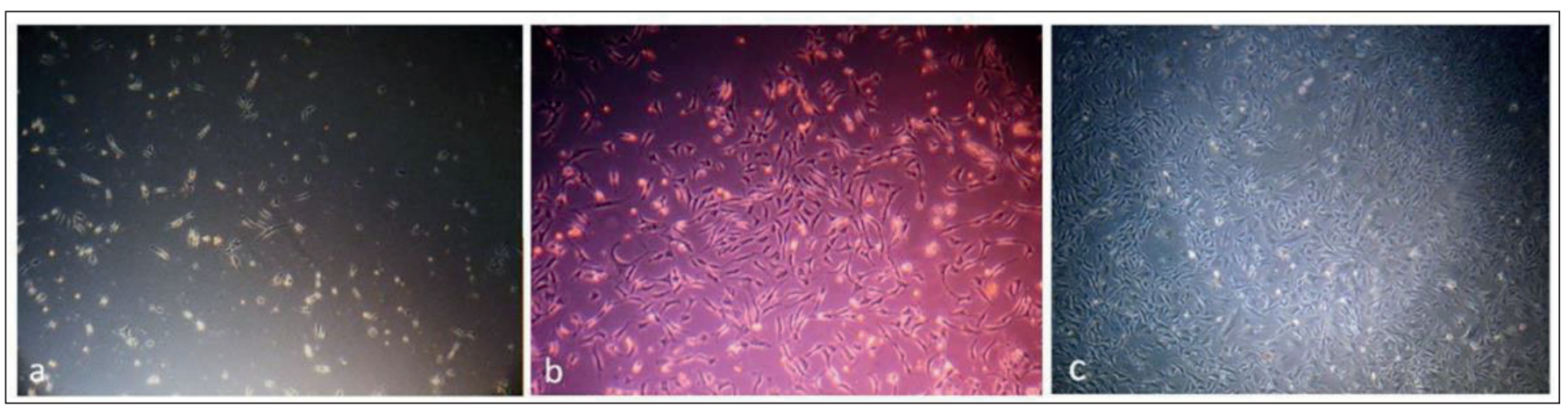

Figura 4. Visualización directa y sin tinción de las ASCs mediante microscopio invertido al segundo día (A), cuarto día (B) y al séptimo día (C) de cultivo celular (Aumento 40X).

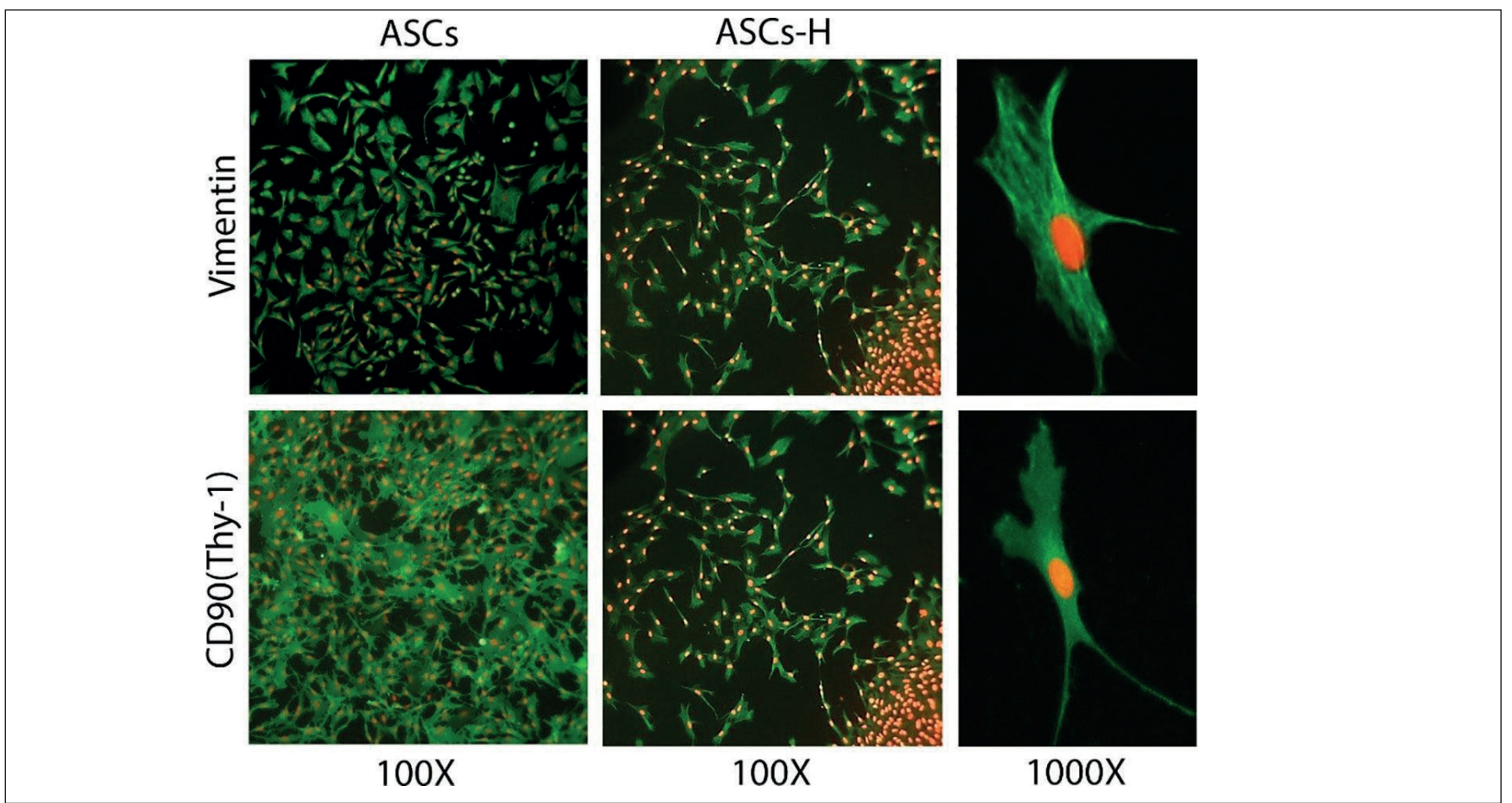

Figura 5. Inmunofluorescencia en ASCs y ASCs-H utilizando anticuerpo primario vimentina 1/100 y CD90 (Thy-1) 1/100 y anticuerpo secundario FITC 1/200 (verde). Tinción de los núcleos celulares con color rojo mediante Yoduro de Propidio (Polysciences) 1/500 (Aumento 100X).

de ASCs-H $1.5 \times 10^{7}+/-1.5 \times 10^{7}$ céls $/ \mathrm{ml}$, manteniendo una viabilidad celular $>99 \%$. Bajo visualización directa mediante microscopio invertido, observamos su adherencia al plástico y la morfología característica tipo fibroblasto a partir del primer cambio de medio de cultivo; al cuarto día, estas células se agrupan formando colonias y al séptimo día ya se puede observar confluencia celular cercana al 90\% (Fig. 4). Mediante inmunofluo- rescencia, obtuvimos tinción positiva indistintamente para el grupo ASCs como para el grupo ASCs-H para el anticuerpo primario vimentina (Dako) 1/100 (marcador de los filamentos intermedios) y CD90 (Thy-1) $1 / 100$ (marcador de proteína de superficie celular). Este último presentó positividad en más del $90 \%$ de las células tanto en condiciones de normoxia como en hipoxia al $2 \%$ de $\mathrm{O}_{2}$ (Fig. 5). 


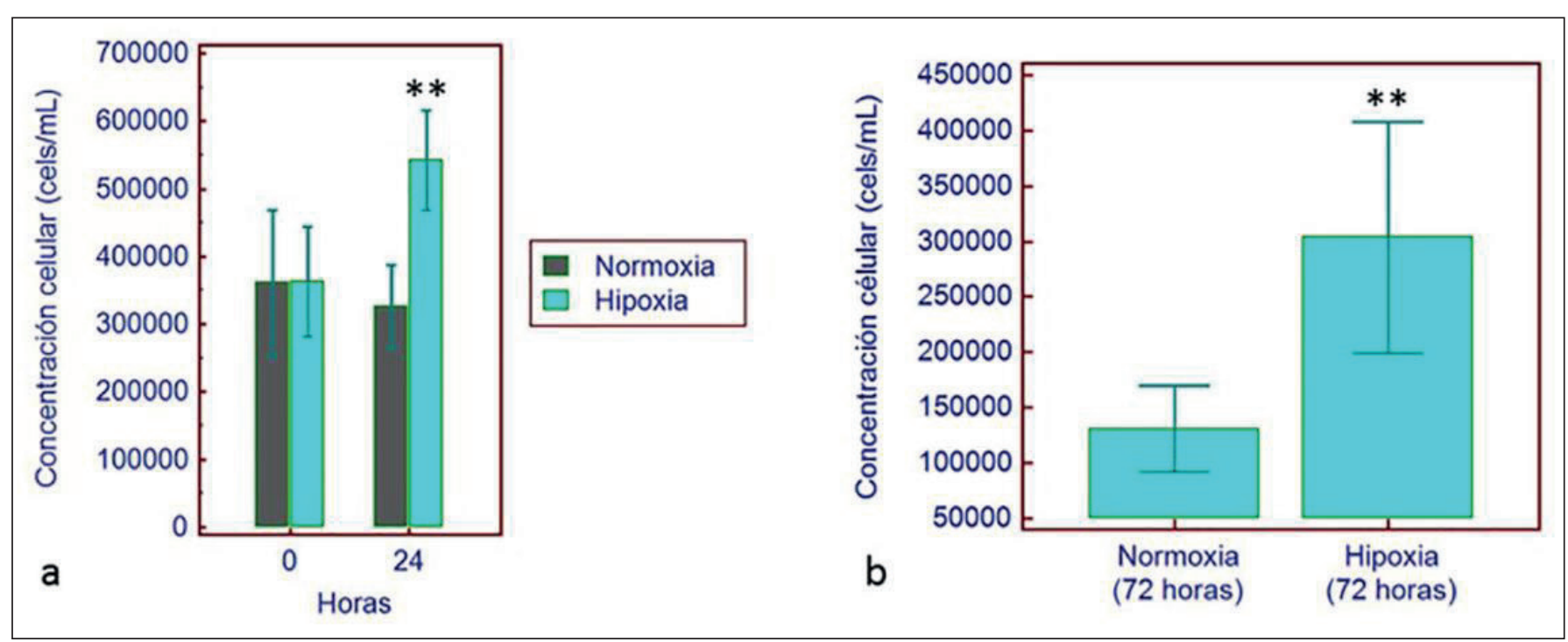

Gráfico 1. llustra aumento en la concentración celular en condiciones de hipoxia a las 24 horas en A y a las 72 horas en B, en comparación al grupo sin precondicionamiento $\left(^{* *}=p \leq 0.01\right)$.

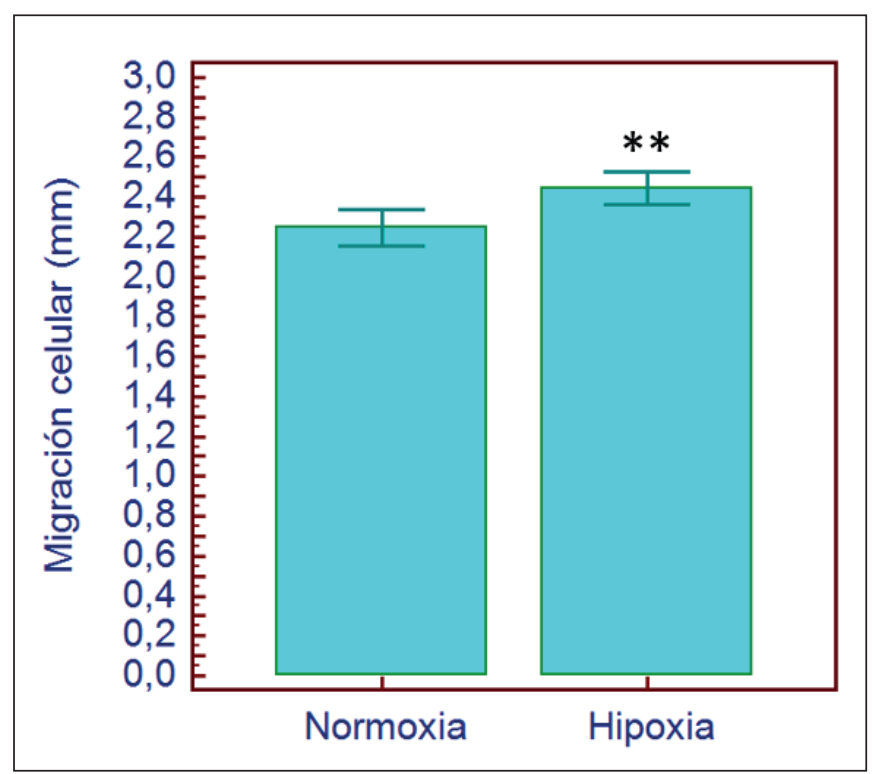

Gráfico 2. Evaluación y comparación de la capacidad migratoria en milímetros de las ASCs y ASCs-H. Medición realizada a las 24 horas $\left({ }^{* *}=p \leq 0.01\right)$.

\section{Estudio de proliferación celular}

Durante el segundo pasaje de cultivo celular de ASCs en condiciones de normoxia hicimos la tripsinización y división en 2 frascos en concentraciones equivalentes, $3.61 \times 10^{5}+/-1.50 \times 10^{5}$ céls $/ \mathrm{ml}$ y $3.63 \times 10^{5}+/-1.14$ x $10^{5}$ céls $/ \mathrm{ml}$ respectivamente $(\mathrm{p}=0.96)$. Después de 24 horas obtuvimos como resultado un aumento significativo de la concentración celular en condiciones de hipoxia $\left(5.42 \times 10^{5}+/-1.03 \times 10^{5}\right.$ céls $\left./ \mathrm{ml}\right)$ en comparación con el grupo en normoxia $\left(3.26 \times 10^{5}+/-8.61 \times 10^{4}\right.$ céls $\left./ \mathrm{ml}\right)$ $(\mathrm{p} \leq 0.001)$.

Realizamos este mismo procedimiento a las 72 horas con otro cultivo celular, logrando la misma tendencia de aumento de proliferación celular en hipoxia con $3.04 \mathrm{x}$ $10^{5}+/-1.13 \times 10^{5}$ céls $/ \mathrm{ml}$ en comparación con el grupo normoxia con $1.31 \times 10^{5}+/-3.71 \times 10^{4}$ céls $/ \mathrm{ml}(\mathrm{p} \leq 0.01)$ (Gráfico 1).

\section{Estudio de migración celular}

Medimos la migración celular a las 24 horas de cada cubreobjeto, obteniendo mayor capacidad migratoria en el grupo en condiciones de hipoxia $(2.24+/-0.82 \mathrm{~mm})$ en comparación con el grupo que se mantuvo en hipoxia $(2.44+/-0.85 \mathrm{~mm})(\mathrm{p} \leq 0.01)$ (Gráfico 2).

\section{Discusión}

Las células madre son una opción terapéutica promisoria para el tratamiento de reparación y regeneración de tejidos. En la actualidad se pueden obtener de distintos tejidos con características similares a las originalmente aisladas de médula ósea. Las células madre derivadas de tejido adiposo adultas cobran importancia ya que se encuentran en forma abundante, son de fácil acceso y es posible lograr diferenciación celular de distintos linajes mesodérmicos. ${ }^{(5)}$ Además es posible lograr inducción para la expresión de marcadores ectodérmicos para la producción de neuronas; por lo tanto se podrían considerar estas células con capacidad pluripotencial. ${ }^{(19)}$ En este trabajo logramos obtener células madre derivadas de tejido adiposo adultas de la zona ínguino-abdominal de ratas. Para poder caracterizar y garantizar que corresponden a células madre, estas presentan características morfológicas que recuerdan a los fibroblastos, poseen capacidad de adherirse al plástico y expresión de marcadores de superficie celular como el CD90 en una proporción mayor al $90 \%{ }^{(7,8,20)}$ y expresión de vimentina que corresponde a filamentos intermedios del citoesqueleto que se encuentra particularmente en células indiferenciadas. ${ }^{(9,10)}$

Uno de los mayores problemas del tratamiento con células madre es el que una gran proporción de estas células mueren en el sitio trasplantado isquémico, situación que podría reducir su eficacia. ${ }^{(3)}$ Es por ello que 
optamos por potenciar estas células en hipoxia al ( $2 \%$ $\mathrm{O}_{2}$ y $5 \% \mathrm{CO}_{2}$ ). Las células madre precondicionadas con hipoxia aumentarían la resistencia a las injurias a través de la expresión de señales protectoras tales como el factor inducible a hipoxia (HIF-1). El complejo HIF-1 está compuesto por 2 subunidades proteicas: HIF-1 $\beta$ que se expresa constitutivamente y HIF-1 $\alpha$ que no está presente en las células normales, se induce y acumula en condiciones hipóxicas, y se degrada en condiciones de normoxia y se acumula rápidamente tras exposición a baja tensión de oxígeno. ${ }^{(21)} \mathrm{La}$ expresión de este factor de transcripción contribuiría a la activación de genes proangiogénicos, genes promotores de la migración celular, genes antioxidantes y protectores de la apoptosis, con mayor tolerancia al trasplante en zonas isquémicas. ${ }^{(21)}$

Dentro de las propiedades de las células madre precondicionadas con hipoxia, pudimos constatar un aumento significativo de la proliferación celular, así como su capacidad migratoria respecto a las células sin precondicionamiento. El aumento de la capacidad migratoria se podría explicar por una regulación al alza de proteínas involucradas en la movilidad celular, ${ }^{(14)}$ así como la expresión de receptores quimiotácticos CXCR4, CXCR7, y CX3CR1 que desempeñarían un rol importante para el reclutamiento de células madre hacia el tejido dañado y su asentamiento. ${ }^{(22)}$ La capacidad de autorrenovación de las células madre es una de sus características clave, por lo tanto es necesario un aumento de la tasa de proliferación para su eficiencia en la terapia regenerativa. ${ }^{(22)}$ Las células madre sometidas a una concentración de oxígeno entre el 2 al 5\% mejorarían la capacidad proliferativa por medio de la expresión del HIF-1 $\alpha$ y el aumento de la expresión de NANOG, que es un regulador de la entrada de la fase $\mathrm{S}$ del ciclo celular. ${ }^{(23)}$

Pudimos corroborar un aumento de la proliferación celular ya a las 24 horas de exposición a hipoxia celular. ${ }^{(23)}$

La translocación y la activación a nivel nuclear sería la causante de la producción de varios genes "río abajo" codificadores de eritropoyetina (Epo), VEGF entre otros, los cuales estimularían los mecanismos endógenos de la angiogénesis..$^{(14,21)}$

Otros genes diana de la HIF-1, como el CXCR4 y codificadores de proteínas de la matriz extracelular (MMPs), estarían involucrados en la migración celular; y otros responderían a mediadores inflamatorios y distintas citoquinas, aumentarían la producción del óxido nítrico sintetasa (iNOS) y la activación de genes antioxidantes. ${ }^{(14,24)}$

También está descrito un aumento de la tolerancia a la apoptosis reflejado por una disminución de la muerte celular in vitro y en el área isquémica o peri-infarto..$^{(14,25)}$

En relación al uso de estas células en heridas y colga- jos, Lee y col. ${ }^{(26)}$ en un estudio en 4 ratas sometidas a 2 lesiones de espesor completo de $8 \mathrm{~mm}$ de diámetro en el área dorsal, evidenciaron que la herida tratada con ASCs precondicionadas con hipoxia mejoraba significativamente su capacidad de curación por medio de una regulación al alza de VEGF y bFGF (factor de crecimiento fibroblástico básico) respecto a la herida tratada con ASCs en condiciones de normoxia. Es interesante que tras la inhibición de VEGF y bFGF por medio de anticuerpos, revirtieron los efectos de migración de los fibroblastos y el proceso de curación de la herida. El efecto de la hipoxia $\left(1 \% \mathrm{O}_{2}\right)$ en las BM-MSCs durante las 48 horas previas al trasplante en colgajo random en ratas, representó un aumento significativo del área de supervivencia del colgajo y de la densidad microvascular respecto al grupo trasplantado de BM-MSCs en condiciones de normoxia $\left(21 \% \mathrm{O}_{2}\right) \cdot{ }^{(3)}$

En el estudio publicado anteriormente por nosotros en esta misma revista, utilizamos esta metodología de precondicionamiento con hipoxia de células madre derivadas de tejido adiposo en colgajos cutáneos aleatorizados en ratas y comparamos respecto al grupo de retardo de colgajo de 5 días y el grupo control. ${ }^{(18)}$ Observamos una disminución significativa en el área de necrosis global del colgajo en los grupos tratados con células madre derivadas de tejido adiposo, con y sin precondicionamiento. Por otra parte, en el grupo de retardo del colgajo y según los patrones de necrosis identificados por medio de características macroscópicas y microscópicas, otorgando una clasificación a esta, observamos necrosis de bajo grado en mayor proporción. Esto significa que se involucra parcialmente y en forma superficial a la dermis, con atrofia y focos de desprendimiento epitelial al séptimo día, que se traducen en una mayor capacidad de reepitelización en comparación al resto de los grupos en los que principalmente el compromiso necrótico del colgajo involucró la dermis en su totalidad.

\section{Conclusiones}

El precondicionamiento de células madre derivadas de tejido adiposo es posible mediante la exposición a hipoxia al $2 \% \mathrm{O}_{2}-\mathrm{CO}_{2} 5 \%$. Objetivamos un aumento en su capacidad proliferativa y migratoria in vitro de forma precoz tras la exposición a hipoxia en el cultivo. Resulta ser un método reproducible para la aplicación de estas células madre precondicionadas a fin de potenciar el tratamiento de distintas enfermedades en humanos.

Este mismo método ya había sido comprobado por nuestro mismo equipo en un modelo experimental en ratas para disminución de la necrosis en colgajos cutáneos aleatorizados. 


\section{Agradecimientos}

A los Drs. David Lemus y Estefania Flores por la revisión y corrección del documento para optar al Grado de Magíster en Ciencias Biomédicas con mención en Morfología.

A Francisco Cortés, Irma Orellana y Alondra Donoso por la preparación de cortes y tinciones histológicas y a Heriberto Coloma por el cuidado de los animales en el Bioterio.

A los Drs. Andrés Stevenson, Felipe Falcón y Jimena Gatica por el estudio y cultivos celulares en el Departamento de Biología Celular y Molecular y Laboratorio de Regulación e Inmunología del Cáncer de la Facultad de Medicina de la Universidad de Chile.

\section{Dirección del autor}

Dr. Miguel Luis Obaíd García

Hospital del Salvador

Avenida Salvador 364

Código Postal: 7500922

Santiago de Chile, Chile

Correo electrónico: miguel.obaid.g@gmail.com

\section{Bibliografía}

1. Bateman ME., Strong AL., Gimble JM., Bunnell BA.. Concise Review: Using Fat to Fight Disease: A Systematic Review of Non homologous Adipose-Derived Stromal/Stem Cell Therapies. Stem Cells. 2018;36(9):1311-1328.

2. James IB., Coleman SR., Rubin JP. Fat, Stem Cells and Platelet-Rich Plasma. Clin Plast Surg. 2016;43(3):473-88.

3. Wang JC., Xia .L, Song XB., Wang CE., Wei FC. Transplantation of hypoxia preconditioned bone marrow mesenchymal stem cells improves survival of ultra-long random skin flap. Chin Med $J$ (Engl). 2011;124(16):2507-2511.

4. Meruane M., Rojas M. Células Troncales Derivadas del Tejido Adiposo. Int. J. Morphol. 2010;28(3):879-889.

5. Mizuno H. Adipose-derived stem cells for tissue repair and regeneration: ten years of research and a literature review. J Nihon Med Sch..2009;76(2):56-66.

6. Friedenstein AJ., Chailakhjan RK., Lalykina KS. The development of fibroblast colonies in monolayer cultures of guinea-pig bone marrow and spleen cells. Cell Tissue Kinet.1970;3(4):393-403.

7. Rebelatto CK., Aguiar AM., Moretão M.P, Senegaglia AC., et al. Dissimilar differentiation of mesenchymal stem cells from bone marrow, umbilical cord blood, and adipose tissue. Exp Biol Med (Maywood).2008;233(7):901-913.

8. Kern S., Eichler H., Stoeve .J, Klüter H., Bieback K. Comparative analysis of mesenchymal stem cells from bone marrow, umbilical cord blood, or adipose tissue. Stem Cells..2006; 24:1294-1301.

9. Nikolić N., Krstić A., Trivanović D, Mojsilović S, Kocić J, Santibanez JF, Jovčić G, Bugarski D. Mesenchymal stem cell properties of dental pulp cells from deciduous teeth. Arch. Biol. Sci.2011;63(4): 933-942.
10. Lama VN., Smith L., Badri L., Flint A., Andrei AC., et al. Evidence for tissue-resident mesenchymal stem cells in human adult lung from studies of transplanted allografts. J Clin Invest.2007;117(4):989-996.

11. Gimble JM., Katz AJ., Bunnell BA. Adipose-derived stem cells for regenerative medicine. Circ Res.2007;11;100(9):12491260.

12. Katz AJ., Llull R., Hedrick MH., Futrell JW. Emerging approaches to the tissue engineering of fat. Clin Plast Surg.1999;26(4):587-603.

13. Jurgens WJ., Oedayrajsingh-Varma MJ., Helder MN., Zandiehdoulabi B., et al. Effect of tissue-harvesting site on yield of stem cells derived from adipose tissue: implications for cell-based therapies. Cell Tissue Res. 2008;332(3):415-426.

14. Yu SP., Wei Z., Wei L. Preconditioning strategy in stem cell transplantation therapy. Transl Stroke Res.2013;4(1):76-88.

15. Park IS., Chung PS., Ahn JC., Leproux A. Human adipose-derived stem cell spheroid treated with photobiomodulation irradiation accelerates tissue regeneration in mouse model of skin flap ischemia. Lasers Med Sci. 2017;32(8):1737-1746.

16. Prasad M., Zachar V., Fink T., Pennisi CP. Moderate hypoxia influences potassium outward currents in adipose-derived stem cells. PLoS One..2014;9(8):e104912.

17. Yang S., Pilgaard L., Chase LG., Boucher S., Vemuri MC., Fink T., Zachar V. Defined xenogeneic-free and hypoxic environment provides superior conditions for long-term expansion of human adipose-derived stem cells. Tissue Eng Part C Methods.2012;18(8):593-602

18. Obaíd M.L., Riquelme R., Calderón W., Raue M., Rojas M. Clasificación y grado de necrosis en colgajo cutáneo aleatorio en ratas tras tratamiento con células madre precondicionadas con hipoxia y retardo del colgajo. Cir. plást. iberolatinoam. 2018; 44(3):259-268.

19. Petersen ED., Zenchak JR., Lossia OV., Hochgeschwender U. Neural Stem Cells Derived Directly from Adipose Tissue. Stem Cells Dev. 2018;27(9):637-647.

20. Dominici M., Le Blanc K., Mueller I., Slaper-Cortenbach I., et al. Minimal criteria for defining multipotent mesenchymal stromal cells. Cytotherapy.2006;8(4):315-317.

21. Salceda S., Caro J. Hypoxia-inducible factor 1alpha (HIF-1alpha) protein is rapidly degraded by the ubiquitin-proteasome system under normoxic conditions. Its stabilization by hypoxia depends on redox-induced changes. $J$ Biol Chem.1997;272(36):22642-22647.

22. Haque N., Rahman MT., Abu Kasim NH., Alabsi AM. Hypoxic culture conditions as a solution for mesenchymal stem cell based regenerative therapy. Scientific.World.Journal. 2013;2013:632972.

23. Forristal CE., Wright K.L, Hanley NA., Oreffo RO., Houghton FD. Hypoxia inducible factors regulate pluripotency and proliferation in human embryonic stem cells cultured at reduced oxygen tensions. Reproduction.2010;139(1):85-97.

24. Mahfoudh-Boussaid A., Zaouali MA., Hadj-Ayed K., Miled AH., et al. Ischemic preconditioning reduces endoplasmic reticulum stress and upregulates hypoxia inducible factor- 1 alpha in ischemic kidney: the role of nitric oxide. J Biomed Sci.2012;19:7.

25. Wei L., Fraser JL., Lu ZY., Hu X., Yu SP. Transplantation of hypoxia preconditioned bone marrow mesenchymal stem cells enhances angiogenesis and neurogenesis after cerebral ischemia in rats. Neurobiol Dis.2012;46:635-645.

26. Lee EY., Xia Y., Kim WS., Kim MH., et al. Hypoxia-enhanced wound-healing function of adipose-derived stem cells: increase in stem cell proliferation and up-regulation of VEGF and bFGF. Wound Repair Regen.2009;17(4):540-547. 